\title{
Congenital Complete Atrioventricular Block
}

National Cancer Institute

\section{Source}

National Cancer Institute. Congenital Complete Atrioventricular Block. NCI Thesaurus.

Code $C 99265$.

A disorder characterized by an electrocardiographic finding of a complete atrioventricular block that manifests during fetal life or soon after birth. It may be isolated or associated with other cong enital heart defects. Isolated cong enital complete atrioventricular block may be associated with maternal connective tissue disorders. 